\title{
A Short Investigation into the Habits, Abundance, and Species of Seals on the North Cornwall Coast.
}

\author{
By
}

\author{
G. A. Steven, B.Sc., F.R.S.E., \\ Assistant Naturalist at the Plymouth Laboratory.
}

(Report to the Ministry of Agriculture and Fisheries-30th December, 1932.)

With Charts I-III.

\section{INTRODUCTORY.}

DURING recent years Cornish fishermen have been complaining bitterly of the damage wrought by seals amongst their several fisheries. The fishing communities in the Lizard and Land's End areas claim that these animals rob their trammel nets and also that they not infrequently disperse shoals of mullet, a single haul of which in favourable circumstances will often yield a large sum of money - enough to ensure for the inhabitants of an entire fishing village a good winter's livelihood.

The most serious charges against the seals have been received, however, from the North Cornwall coast. The fishing communities situated along that shore complain that the seals frequent the herring fishing grounds and remove from the drift nets many of the herrings which have become enmeshed therein. The loss of fish thus entailed does not seriously embarrass these men in a good fishing season. But when fish are scarce and the catches small it is claimed that the activities of the seals constitute a grave menace to their already precarious livelihood.

According to reports sent in by the fishermen, the Grey Seal is the chief offender in this respect.

At the request of the Ministry of Agriculture and Fisheries, the Director of the Plymouth Laboratory of the Marine Biological Association instructed the writer to visit some of the Cornish fishing ports during the present herring season and find out by direct observation* with the

* It must here be pointed out that herring drifting takes place mainly during the hours of darkness. The fishing vessels leave harbour in time to reach the fishing grounds at or just before sundown. Opportunity for the clear observation of seals and their activities amongst the boats and by the fishing nets is restricted therefore to the hours of failing daylight when the boats are proceeding to the grounds or while they are returning to harbour after daybreak - if they remain out until that time. After darkness falls, unless in very bright moonlight, a seal can be seen only if it should come within the circle of light cast upon the water by the boat's fishing lamps.

NEW SERIES.-VOL. XIX. NO. 2. MAY, 1934. 
fishing fleets to what extent these complaints are justified, and at the same time to determine - if possible - whether Grey Seals are numerous in the area.

The observations made and the results obtained form the substance of this report.

\section{Places Selected.}

It was ascertained from the Cornwall Sea Fisheries Committee that serious complaints concerning the depredations of seals are most frequently received from the fishermen of St. Ives, Port Isaac, and Padstow. Arrangements were accordingly made to go to sea with one of the herring drifters operating from each of those places. Owing to the success which attended the work at the two first-named ports, Padstow was not visited. At the special request of the Chairman of the Cornwall Sea Fisheries Committee, however, a visit was paid to Sennen Cove, near Land's End.

It was found that the Sennen fishermen, having heard that an investigation was in progress, wished merely to make verbal testimony to the damage wrought by seals amongst their several fisheries. It is from this village, for example, that the complaints regarding trammel nets and mullet shoals mainly have emanated. As no trammels were in use at the time of the visit and no mullet shoals in the vicinity, more direct evidence* of the activities of the seals in that locality could not be obtained. Two attempts were made, however, to visit the Longships Rocks where, the fishermen stated, seals may frequently be seen in considerable numbers. Although the sea was calm in Sennen Bay it was found to be too rough outside to approach the Longships on both the occasions on which an attempt was made.

\section{The Seal Menace.}

As will be seen from the Appendix (p. 496) subjoined to this report, three trips were made to the herring grounds in the vicinity of St. Ives in a herring drifter normally employed in fishing. While thus accompanying the herring fleet, five seals were sighted.

None were observed during the first night at sea in the vicinity of Cligga Head and Perran Beach (see Chart II, p. 499). On the second evening three seals were passed on the way to the fishing grounds off Zennor Head, only about 5 miles distant from the harbour (see Chart I, p. 497). Another seal was later observed about 150 yards away from the boat while the nets were being "shot." On the following morning in the vicinity of Pen Enys Point, a very large seal was seen within the circle of light cast by the boat's fishing lamps. It appeared to have come from the direction of the land, but just as it was sighted it turned towards the near

* Which was the object of this investigation. 
net along the side of which, swimming rapidly, it disappeared outwards in the darkness.

During the single night spent at sea in Port Isaac Bay eight seals were sighted (see Appendix, p. 500). Before reaching the fishing ground only 2 miles distant from the harbour, three seals were passed. One of these appeared and disappeared several times by the side of another boat's train of nets. A fourth seal subsequently appeared close by the corkrope supporting our own near net and a fifth about half-way along it. The latter disappeared in the gathering darkness following the line of the cork-rope. A sixth seal made its appearance a short distance to seaward of the boat. While the nets were being hauled, one seal remained for a considerable time close behind the vessel's stern, apparently following in her wake as she moved slowly along. Still another made its appearance near the outer edge of the illuminated area around the boat hard by the side of the net which was then being hauled in. Several times this seal disappeared only to reappear in the same relative position.

These are all the observations which were made actually with the fishing fleets at sea. More time spent with them would have produced only a needless repetition of the same kind of data without adding in any way to the value of those already obtained* - which show very clearly that seals are numerous on the North Cornwall inshore herring fishing grounds and that they do haunt the nets of the herring drifters.

\section{Abundance of Seals.}

In addition to keeping a look-out for seals on the fishing grounds, two special exploratory cruises were made in search of them. From St. Ives, on Monday, 21st November, a cruise was made along the shore, eastward from the harbour, as far as Basset Island, where seals are reported to be very numerous (see Appendix and Chart III, p. 500). Only four seals were sighted during the entire trip which extended to about 18 milest and occupied approximately three hours. This may have been due to the fact that a heavy ground swell was running, and it is much more difficult to catch sight of a dark object in the water when its surface is very broken and uneven than when it is calm and smooth. It is of particular interest to note, therefore, that on Monday, 5 th December, over 100 seals of all sizes were reported to have been seen lying on a sand beach at the foot of a cliff on the mainland immediately opposite Basset Island. This beach is inaccessible except by sea, and then only in calm weather.

* See also p. 494 of this report.

$\dagger$ On the return journey a "wide circle " was made to seaward as it was thought tha' the stormy sea might have caused the seals to forsake the immediate vicinity of the rocks. 
On Wednesday, 7th December, a visit was paid to some caves-locally known as "seal holes"- about two miles west from Boscastle, in which seals were said by the Port Isaac fishermen to make their homes and to breed. All but one of these caves are inaccessible except by sea, and it was just about high water when they were reached by boat from Port Isaac. The caves are four in number,* situated close together some hundreds of yards north of the Gull Rock (also known as Beeny Island). All have relatively very small openings in the face of high rocks. One of the openings was too small for a boat to enter it, but the cave could be seen to "open out" inside to unascertainable dimensions. A second cave had its opening completely submerged so that it became visible only when the water subsided between successive waves. The two others it was found possible - though difficult because of the swell-to enter.

The northernmost cave was penetrated for a distance of about 100 yards. Here further progress was checked by the complete darkness ahead. Even at this distance from its mouth the water in the cave was over 8 feet deep and it was sufficiently disturbed to make an unseen rock a dangerous obstacle in the way of the heaving dinghy. It was possible to make out, however, that at this point the tunnel-like neck of the cave expanded into a vast cavern in which the troubled waters made loud and fearsome noises. No seals could, of course, be discerned in the darkness, and, unfortunately, no lantern was available.

On arrival at these caves not a single seal was to be seen. On emerging again from the first one entered, and in which a commotion had been made by beating empty petrol cans and buckets, a large number of seals were found to have made their appearance. They were in a state of much activity and excitement, diving and reappearing with great frequency, but always remaining close to the base of the cliffs.

The second accessible cave was then entered but its roof was so low that the rise and fall of the surging sea made it dangerous to venture far for fear that the dinghy might be crushed against the rocks above and swamped. On coming out, still more seals were in evidence. Loud noises were made at the mouths of the other two caves, which could not be entered because of the conditions prevailing, in order to cause the seals to come out if any were inside.

Because of the rough sea a more thorough exploration of the caves was impossible. There can be but little doubt, however, that the seals which made their appearance in the sea at their mouths had emerged from them. Having been disturbed, they came out - as was to be expected - under the water, which was then sufficiently deep in all the caves for them to emerge unseen. One large seal was observed, however, swimming rapidly out of one of the caves on the surface of the sea, and two

* There are other "seal holes" in this vicinity which were not visited. 
others on being approached disappeared into the submerged opening already mentioned.

At the end of $1 \frac{1}{2}$ hours in the vicinity a great many seals had appeared. Their number could not be ascertained with any degree of accuracy as they were in a state of too much activity. Nevertheless, six or seven heads were generally to be seen on the surface at one time, and in one instance no less than nine different seals were in view near the mouth of one cave at the same moment.

It can safely be stated, therefore, that in addition to the numerous seals scattered over the various herring grounds at this time, there is at least one seal colony of considerable size in the vicinity of Boscastle, on the North Cornwall coast. It is probable that there are other such colonies in the same locality and at other places along that county's northern shore. Little evidence has as yet been collected which will either support or contradict the view that these seal resorts may also be breeding places. It may be significant, however, that among the seals which were seen near Boscastle there were several very young individuals* present among others which were obviously old adults.

\section{Species of Seals.}

It is very difficult, while actually at sea, to distinguish with certainty the Brown Seal (Phoca vitulina) from the Grey Seal (Halichorus grypus) unless a clear view of the animal can be obtained at very close range. When, in the course of this investigation, a seal was sighted, but in such conditions that identification was impossible, the animal was recorded simply as "SEAL." When a better view was obtained and the species could be determined with reasonable certainty, this additional information is added to the log (see Appendix to this report). It is clearly to be understood, however, that these tentative identifications of live animals must be considered fallible and by no means final.

It will be seen in the Appendix that for only five animals are such identifications given. Of these, one is recorded as a Brown Seal and four as Grey Seals. In addition, all those seen near Boscastle appeared to be Grey Seals. If these identifications are correct, it would appear that the Grey Seal (Hatichorus grypus) is much the more common of these two species along the shores of Cornwall. This conclusion is supported by the fact that the seal which was washed up dead on the beach at Porthminster, near St. Ives, was found on examination to be Halichœrus grypus. Two other dead seals were later washed ashore near St. Ives both of which were also Halichœrus grypus.

* See also p. 494 . 


\section{Discussion of Results.}

Although there can be no doubt that seals do haunt the nets of the herring fishermen along the North Cornwall coast, definite proof that they actually rob the nets could not be obtained. Nor will this information readily be secured simply by making observation from a herring drifter normally employed. For complete elucidation of this problem a separately-conducted investigation would be required and special methods adopted or devised. If fish are removed from the nets by seals, this is done under water where - except in exceptional circumstances - their actions cannot be observed. An investigator might, therefore, spend a whole season, or even many seasons, in an ordinary fishing boat without adding materially to the information contained in this report. He might not for a long time be fortunate enough even to catch sight of a seal rising to the surface with a fish in its mouth* - an observation which the Cornish fishermen claim occasionally to make and to which they attach very great significance. For the purpose of their argument in favour of the destructive activities of seals they ignore the fact that some herrings are always lost from herring nets before they can be hauled inboard. In the absence of definite proof one way or the other two possibilities must, therefore, be kept in mind: (1) that the seals are attracted to the nets by these "dropped " herrings (which sink to the sea bottom where, in shallow water, they form an easily available food supply); and (2) that the seals definitely rob the nets.

One thing, however, is certain. Very seldom indeed does a seal become entangled in a drift net or is it responsible for causing damage to it in any other manner whatsoever. This statement can be made with complete confidence. It is backed by the present observer's knowledge of seals in other localities and the Cornish fishermen acknowledge that it holds good also in their waters.

As regards the species of seal at present found on the Cornish fishing grounds, it is interesting to note that the Grey Seal (Halichorus grypus) was recorded from the North Cornwall coast as long ago as 1883. In that year Sir E. Ray Lankester found a newly born Grey Seal on the shore at Pentargon Cove, near Boscastle, and had it conveyed to the Zoological Gardens, Regent's Park, but it soon died in captivity. Lankester believed, however, that the Grey Seal was extremely rare in Cornwall and that the Brown Seal was the more abundant species (Diversions of a Naturalist, 1915 ; p. 32 et seq.). The very opposite appears to be true at the present time. This fact is of particular importance in view of the statement made by Hjort and Knipowitsch (Rapports et Procès-Verbaux, Vol. VIII,

* On one occasion, many years ago, the writer himself caught sight of a seal rising to the surface of the water with a fish (not a herring) in its mouth. 
1907 ; p. 114) concerning the Grey Seal. According to these authors " fish form its main food and it is in the Baltic, probably, the most harmful of the three species, occurring there." The stomachs of three individuals of this species from the vicinity of St. Ives have been examined with the following results.

Date Examined.

$21 / 11 / 32$

$28 / 11 / 32$

$13 / 12 / 32$
Locality where found. Porthminster (St. Ives).

St. Ives.

St. Ives.
Stomach Contents.

Herring Bones and traces of Herring Spawn.

Beak of Cuttlefish (Sepia sp.).

Clupeoid remains.

These data from Cornwall are too scanty as yet to justify any. definite conclusion being drawn from them other than that fish (herrings) do to some extent enter into the diet of the Grey Seal in those waters.

Little is known, and the present writer has been able to find out nothing, concerning the breeding places (if any) of seals in Cornwall. Lankester (op. cit., p. 33) was of opinion that whilst " the Brown Seal produces its young most usually in caves or rock-shelters, the Great Grey Seal chooses a remote sand island or deserted piece of open shore for its nursery." Sufficient evidence is not available to settle the question of whether or not this statement is justified - at any rate as far as the Cornish coast is concerned. Unless the present writer be in error concerning the seal colony at Boscastle, Halichorus grypus is an inhabitant of caves in that locality. It probably also breeds there. (See also p. 492 of this report.)

The presence or absence of a cave-dwelling habit will have a marked effect upon the results which will attend any effort to reduce the numbers of seals. If a reward be offered for every head produced few seals will meet death by shooting, as only a small percentage of the animals so killed are recoverable. Two other methods will probably be extensively employed: (1) that of entering the caves in which seals are known to congregate and killing as many as possible with heavy cudgels; and (2) that of driving them out of such caves to be entangled in strong nets previously fixed across the cave openings. Both these methods of hunting were formerly practised in Cornwall when the killing of seals was a profitable pursuit because of the good prices which could be obtained for their skins and oil. It is possible that the netting method, if intensively employed, will reduce cave-frequenting species to the point of extinction in a very short time - say, in a single year. If, therefore, rewards are to be offered for the destruction of seals in Cornwall it is, in the writer's opinion, highly desirable that a detailed survey of their ordinary haunts and breeding places be undertaken in order to assess as accurately as possible the relative abundance of the Grey and Brown species and to obtain reliable 
knowledge of their separate habits. If it is the Grey Seal which is abundant on the Cornish coast, the complete extermination of this attractive and interesting member of the British Marine Mammalian Fauna from a locality which, apparently, it finds congenial, seems scarcely to be desirable. Should such a survey as that suggested above be carried out, periodic return visits to the Grey Seals' ordinary haunts and breeding places (say, once a year during the breeding season) would serve to reveal the extent of the depletion which was being brought about in their numbers.

\section{SUMMARY.}

1. In the course of three trips to the herring grounds in the vicinity of St. Ives five seals were sighted. Seven others were also seen at various other times and places in the course of five days spent in that locality.

2. During a single night at sea in Port Isaac Bay eight seals were sighted.

3. It was obvious from the movements of certain of the seals observed on the fishing grounds that they were attracted to the herring nets.

4. Direct evidence that the seals actually remove fish from the nets was not obtained.

5. Damage done to drift nets by seals is negligible.

6. Grey Seals (Halichorus grypus) are present in considerable numbers, and are probably the commonest seals in Cornish waters.

7. Brown Seals (Phoca vitulina) appear to be few-they may even be rare-around Cornwall.

8. There is at least one seal colony of considerable size in certain caves near Boscastle. This appears to consist of Grey Seals. Probably other such colonies exist on the Cornish coast.

9. Clupeoid remains have been found in two out of the three Grey Seal stomachs which have been examined.

10. Further and more exact knowledge of the habits and relative abundance of Grey and Brown Seals around the Cornish coast is desirable.

\section{APPENDIX.}

Detailed Log of Observations and Events.

Thursday, 17/11/32.

2.30 p.m. Arrived St. Ives.

3.45 p.m. Went on board M.B. Grateful (J. Boase, Master) which put to sea immediately for the fishing grounds.

6.05 p.m. Commenced "shooting" nets (14 in number) off Cligga Head (see Chart II). Wind NNE. Innermost (off-end) net about $\frac{1}{2}$ mile from the shore. 
No seals were sighted along the whole route to this fishing ground, nor did any appear within range of the lights while fishing was in progress during the night. There was thus absolutely no evidence of the presence of seals obtained during this trip.

Friday, 18/11/32. (St. Ives.)

\section{(See Chart I.)}

3.50 p.m. Proceeded to sea in Grateful.

3.55 p.m. 1 seal (large brown)-sighted some distance to seaward of St. Ives Head, just outside St. Ives harbour.

4.10 p.m. 1 seal-swimming close to the rocks at Clodgy Point.

4.16 p.m. 1 seal-in small bay between Hor Point and Pen Enys Point.

4.54 p.m. Commenced "shooting" nets off Zennor Head. Wind NNE. Innermost (near) net about $\frac{1}{4}$ mile from the shore.

5.15 p.m. Nets all out.

1 seal-sighted about half-way between boat and shore. (Made several appearances more or less in the same place after first seen.)

7.30 p.m. "Looked at" nets. No herrings and "nets all on fire." Successful fishing, therefore, considered impossible. Commenced hauling.

9.15 p.m. Boat returned to harbour.

Four seals were sighted on this trip. They are obviously fairly common around the rocks westward from St. Ives. But no seal approached the nets

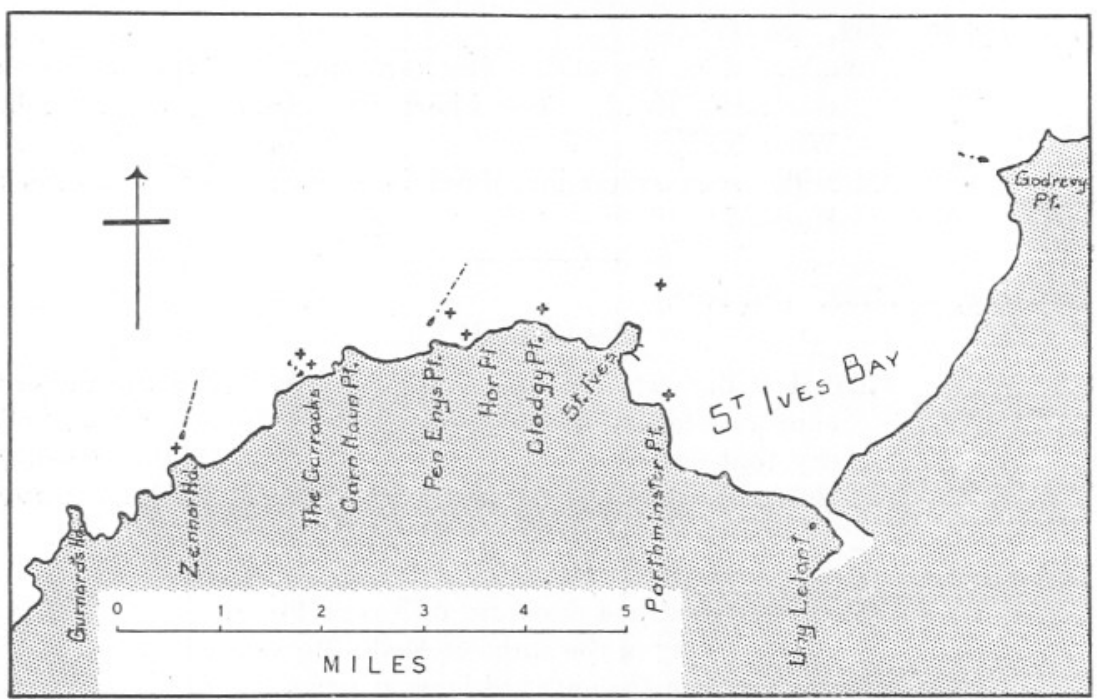

Chart I.-North Cornwall Coast-Gurnard's Head to Godrevy Point. $+=$ Seals seen on 18th, 19th, and 20th November.

- - . - . . . = Position where m.b. Grateful shot her net on 18th (evening) and 19th (morning). 
while it was still light enough to see; and when hauled up they showed no signs of having been visited in the darkness.

Saturday, 19/11/32. (St. Ives.)

3.50 a.m. Left again for fishing ground.

4.55 a.m. Commenced "shooting" off Pen Enys Point (Chart I). Innermost (near) net about 300 yards from the shore.

5.15 a.m. Nets all out.

1 seal-appeared within circle of light cast by boat's lamps ; swimming from direction of the shore; remained visible for short time and then disappeared in the darkness along the side of the near net.

8.35 a.m. Returned to harbour with about 700 herrings.

The single seal observed on this short trip was very definitely " making for " the nets.

2.30-6.15 p.m. Walked along the shore- eastward from St. Ives as far as Uny Lelant. Wind NNE. Heavy ground swell beginning to come in.

1 seal* (small grey)—observed at Porthminster Point, a few yards out from the rocks. No more were seen, though several reported to be in the vicinity by some boys playing on the beach.

Sunday, 20/11/32. (St. Ives.)

Walked along the cliffs-westward from St. Ives-as far as Gurnard's Head. (See Chart I.) Heavy ground swell. Wind NNE.

2 seals-seen swimming about in the sea near the Carrack Rocks.

Monday, 21/11/32. (St. Ives.)

(See Chart II.)

Hired M.B. Grateful for exploratory cruise along the eastern shores as far as Basset Island. The fishermen of St. Ives say that seals are usually more numerous in that locality than anywhere else in their area. $\dagger$ Wind N. Very heavy ground swell.

9.15 a.m. Left St. Ives harbour.

10.13 a.m. 1 seal-sighted just eastward of Navax Point.

10.35 a.m. 1 seal-playing in the surge at Hell's Mouth.

No more seals were seen on the outward journey or at Basset Island.

* On Thursday, 17th, a small seal, swimming around the same rocks, was sighted from the train just before it entered St. Ives station. This may have been the same animal.

$\dagger$ See also p. 491 of this report. 
Steered in a "wide circle" to seaward on the return journey.

11.42 a.m. 1 seal-in centre of St. Ives Bay.

12.03 p.m. 1 seal (very large grey)-playing in the breakers at Porthminster Point, just outside St. Ives harbour and to the westward of it.

Four seals (one grey) were sighted on this trip. The rough sea made it very difficult to observe dark objects amongst the waves.

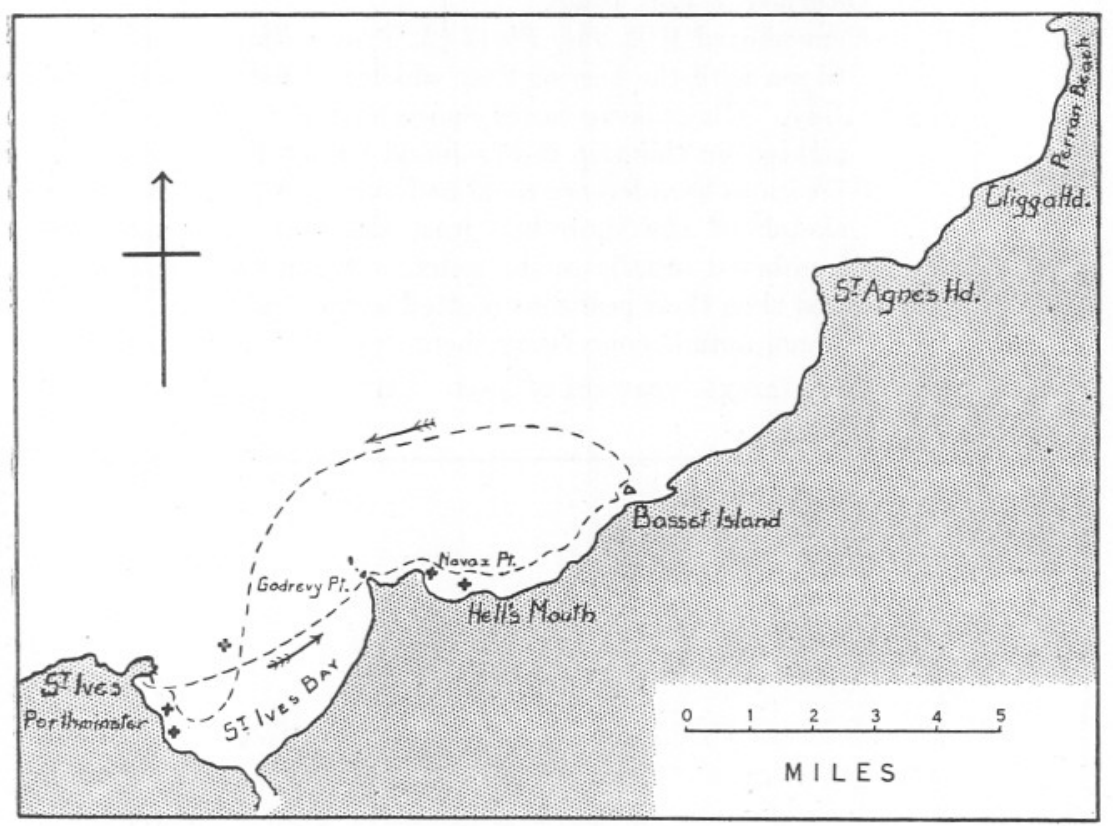

Chart II.-North Cornwall Coast-St. Ives Head to Perran Beach. $+=$ Seals seen on 21 st November.

$-\ldots-\ldots=$ Route of exploratory voyage undertaken on that day.

3.20 p.m. Examined a large seal which had been washed up dead on Porthminster Beach. This proved to be a large female Grey Seal (Halichœrus grypus). The head was removed and forwarded to the British Museum where this identification was confirmed.

Stomach contents : Herring bones and some remains of herring spawn.

7.00 p.m. Left for Plymouth.

Wednesday, 23/11/32.

Proceeded to Port Isaac. Found the sea too rough there to allow the boats to go out on that evening. Remained overnight. 
Thursday, 24/11/32. (Port Isaac.)

Weather still bad. Made arrangements to be recalled immediately the weather moderated sufficiently to allow fishing to be resumed, and returned to Plymouth.

Tuesday, 6/12/32.

\section{(See Chart III.)}

Returned to Port Isaac.

Went aboard M.B. Boy Fletch (A. Provis, Master) and put out to sea with the herring fleet which was fishing in Port Isaac Bay. (In making notes concerning the seals which were sighted on this trip it was found impossible to record their positions by reference to named points on the land. A rough sketch of the shore-line was, therefore, made, the seals numbered serially in the order in which they were sighted, and then their positions plotted as on Chart III. The additional details concerning them are given below.)

3.49 p.m. 1 seal (grey)-seaward of boat.

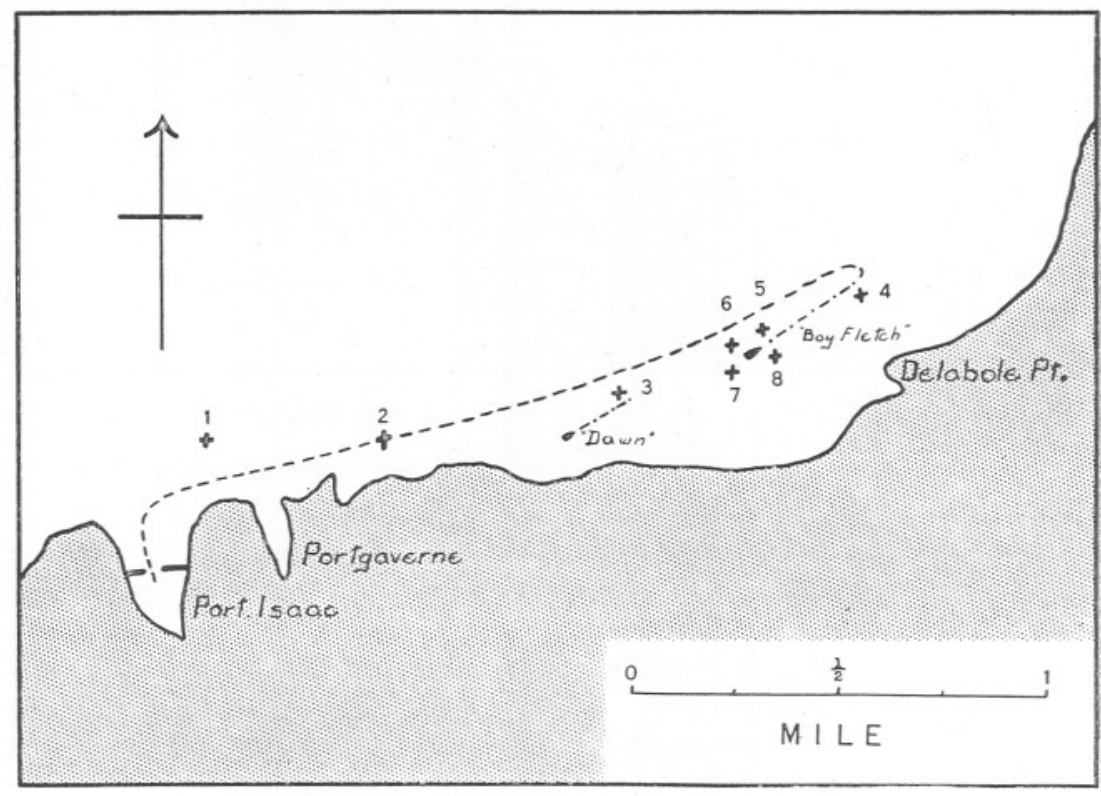

Chart III.-North Cornwall Coast-Port Isaac Harbour to Delabole Point. $+=$ Seals* seen on 6 th December.

-...... = Positions of nets of Dawn and Boy Fletch on shooting.

$-\ldots-\ldots=$ Course of Boy Fletch to fishing ground.

* In plotting positions of the Seals the small changes in position occupied by the nets owing to drift have been ignored. 
4.03 p.m. 1 seal (small grey)-rose to the surface about 20 yards ahead, right in the boat's track ; dived immediately (but reappeared astern several times in the next 5 minutes).

4.17 p.m. 1 seal-hard by the cork-rope of the outermost (off-end) net of another fishing boat, the Dawn, which was then shooting the last of her nets. (3)

4.33 p.m. Commenced shooting nets (13 in all) off Delabole Point.

4.36 p.m. 1 seal (small)-bobbed up beside the cork-rope of our first net but promptly disappeared again. (4)

4.49 p.m. 1 seal-sighted close alongside near net, about half-way along it ; disappeared in the gathering dusk following the direction of the cork-rope.

5.36 p.m. 1 seal (small) — close by and to seaward of boat. Possibly same as No. 4 above.

7.00 p.m. Commenced hauling.

7.23 p.m. 1 seal (large)-about 6 yards behind the stern of the boat; appeared to be following her as she moved along. (7)

1 seal-also sighted at the same time by the side of the net which was then being hauled inboard, near the outermost edge of the circle of light. (Disappeared and reappeared several times.)

Eight seals were sighted on this trip, six of them in the immediate vicinity of herring nets or of a fishing boat while her nets were out. There can be no doubt that seals were numerous at this time in Port Isaac Bay, and that they were attracted to the herring nets.

Wednesday, 7/12/32. (Port Isaac.)

Visited seal caves at Boscastle (see p. 492 of this report).

Friday, 9/12/32, and Saturday, 10/12/32.

At Sennen Cove (see p. 490 of this report). 
